\title{
Epigenetic Error and Large-scale Genomic Instability in Cancer
}

\author{
Patrick A Riley* \\ Totteridge Institute for Advanced Studies, UK
}

Received: May 03, 2018; Published: May 10, 2018

*Corresponding author: Patrick A Riley, Totteridge Institute for Advanced Studies, The Grange, Grange Avenue, London N20 8AB, UK

Keywords: Epigenetics; DNA Methylation; Chromosomal Instability; Cancer

\section{Introduction}

\section{Epigenetics and DNA Methylation}

From an evolutionary point of view, it is likely that epigenetic markers arose as a means of protecting genetic information [1]. The primary epigenetic marker is DNA methylation and DNA methylation would furnish a way to distinguish between 'self' and 'foreign' genetic material as, for example, for the selective action of the restriction endonuclease system in bacteria [2]. Such an epigenetic marker might plausibly have become subsequently recruited to enable the stabilization of alternative phenotypic states in differentiated tissues of multicellular organisms, as envisaged by Waddington $[3,4]$. For terminally differentiated tissues in which no further cell division takes place, such as CNS neurons, there is no mechanistic difficulty in retaining the status quo, but in order to maintain the stable differentiated phenotype of cells with identical genomes undergoing replication it is necessary for the epigenetic information to be duplicated. The significance of DNA methylation in conferring phenotypic stability to differentiated proliferating cells was proposed by Holliday and Pugh [5] and Riggs [6].

The DNA methylation copying process involves a DNA methyl transferase 1 complex which recognizes and binds to segments of DNA containing hemi-methylated $\mathrm{CpG}$ dinucleotides in the duplicated strands formed by semiconservative DNA replication and converts them to fully methylated copies of the original $[7,8]$. The primary importance of DNA methylation patterns rests on their ability to selectively recruit the binding of various protein complexes including histones and sets of enzymes able to modify histones such as histone acetylation and deacetylation complexes and histone methyl transferase complexes which affect the structure of nucleosomes.

\section{Nuleosome Structure}

In eukaryotic genomes the nucleosome core particles consist of an octamer of two copies each of the core histones (H2A, H2B, $\mathrm{H} 3$, and H4) round which 146 bp DNA is wound in two turns of a left-handed superhelix $[9,10]$. Although core histone structures are strongly conserved there are variants of $\mathrm{H} 2 \mathrm{~A}$ and $\mathrm{H} 3$ (such as H2AZ macroH2A, and H33 and CENP-A). In addition there are post-translational modifications of the core histones including acetylation, methylation, ubiquination and phosphorylation. The effect of these substitutions and histone modifications is to create differing epitopes that determine the binding of various macromolecular complexes.The packaging of chromatin is dependent on the structure of nucleosomes mediated through modification of histones. This in turn is directed by the local pattern of DNA methylation, which is thus the primary determinant of chromatin architecture.

\section{Chromatin Architecture}

Chromatin is the ultimate carrier of heritable epigenetic information. Four general categories of chromatin are recognised: euchromatin, in which the nucleosomes are readily accessible to transcription factors; heterochromatin, in which the nucleosome structure is not normally accessible for transcription; centromeric chromatin, a densely compacted region of chromatin that provides attachment sites for kinetochore proteins and spindle microtubules; and pericentromeric chromatin, which acts as a centromere boundary. Chromatin organisation is usefully defined in terms of the histone variants with which they are associated. The structural category of chromatin and some of the associated histone modifications are summarised in Table 1. 
Table 1: Chromosomal architecture and histone modifications.

\begin{tabular}{|c|c|c|c|c|}
\hline $\begin{array}{c}\text { istonevariant or } \\
\text { modification }\end{array}$ & Euchromatin & Heterochromatin & Centromere & Pericentromere \\
\hline H3K4me2 & - & & • & \\
\hline H3K4me3 & $\bullet$ & & & \\
\hline Н3К9ас & $\bullet$ & & & \\
\hline H3K9me2 & & - & & \\
\hline H3K9me3 & & $\bullet$ & & - \\
\hline Н3К27me3 & & $\bullet$ & & \\
\hline H3R2me & & - & & \\
\hline H4K20me2 & & & & $\bullet$ \\
\hline H4K20me3 & & • & & \\
\hline CENP-A & & & • & \\
\hline H2A.Z & & & $\bullet$ & • \\
\hline H3S10P & & $\bullet$ & $\bullet$ & $\bullet$ \\
\hline H3S37P & & & • & \\
\hline Н3Т3Р & & & $\bullet$ & \\
\hline H4S1P & & & - & \\
\hline
\end{tabular}

The characteristic distribution of variant or modified histones shown in the left hand column is indicated by a filled circle $(\bullet)$ in the chromatin categories listed. The phosphorylated variants shown in the Table are mainly generated during mitosis by kinases such as the aurora kinases which are directed to the appropriate binding sites by structural cues.

\section{Chromosomal Instability In Cancer}

The fundamental biological abnormality of cancer is the breakdown in multicellular organisms of the normal controls that restrict competition between cells exhibiting different functional characteristics and permit intercellular cooperation.The nature of the crucial abnormalities exhibited by malignant cells is not clear, although abnormal migratory capability and dysregulated proliferation appear to be essential components, and the evidence indicates that these properties arise from large-scale disturbances of the genome.The cytological diagnosis of cancer rests on a number of criteria. The recognised cellular features of malignancy include cellular enlargement, increased nuclear/cytoplasmic ratio, nuclear hyperchromasia, prominent and large nucleoli, abnormal distribution of nuclear chromatin, the presence of abnormal mitoses, as well as nuclear membrane abnormalities and cellular and nuclear pleomorphism.

These criteria essentially reflect various aspects of chromosomal instability (CIN) which include chromosome doublings, chromosomal fragmentation and other abnormalities occurring during mitosis. This results in large-scale chaotic changes to the genome of cancer cells and the expression of abnormal characteristics, some of which endow the cells with malignant potential such as the ability to transgress normal tissue boundaries and migrate to distant sites. Chromosomal instability is associated with alterations in chromatin structure, particularly those involving centromere defects.

\section{Centromere Chromatin Structure}

The location of regions of euchromatin and heterochromatin are regulated by the pattern of DNA methylation and there is much evidence that the location of the centromere is similarly determined epigenetically [11-15]. Epigenetic determination of the centromere locus provides a mechanism for karyotypic evolution [16], a phenomenon that appears to underlie much of the chromosomal instability in cancer cells. Centromeric and pericentromeric DNA is normally heavily methylated and loss of DNA methylation of this region is associated with segregation defects [17-19]. The pattern of DNA methylation within the centromere consists of specific nonmethylated zones within extensively methylated regions. The nonmethylated sites are recognised by the kinetochore protein CENP-B which, with CENP-A and CENP-C, binds to a region of $\alpha$-satellite DNA which is important for establishing kinetochore location and preventing duplication [20].

The histone modifications of centromeric chromatin are distinct from constitutive heterochromatin. The highly conserved histone CENP-A substitutes for H3 in some centromeric nucleosomes [16] and centomeric chromatin is composed of alternating zones of $\mathrm{H3}$ and CENP-A-containing nucleosomes [17]. CENP-A is a central factor in recruiting proteins that are essential for kinetochore assembly and progression during mitosis [15,18]. H2A.Z is a variant of H2A present in non-CENP-A nucleosomes and appears to promote sister chromatid adhesion prior to chromosomal segregation [19].

\section{Pericentromere Chromatin}

H3K9 and H4K20 methylases accumulate in the pericentromeric region at mitosis [21] and pericentromeric chromatin includes nucleosomes containing the histone $\mathrm{H} 3 \mathrm{~K} 9 \mathrm{me} 3$, but these are located distal to the centromere and may establish a boundary signal to avoid expansion and duplication of the centrosome [22]. Although many of the details of the processes involved remain to be elucidated, it is clear that DNA methylation affects chromosomal stability through chromatin remodeling and the recruitment of 
specific factors that are central to the controlled distribution of the cellular genome at mitosis and that this epigenetic signal is critical to genomic stability [23]. The importance of DNA methylation in cancer is well established [24-26]. DNA methylation patterns are intimately linked to chromatin structure [27] and exert their influence through interaction with histone-modifying enzymes $[28,29]$ and by affecting the association with, and activity of, methylation-binding proteins involved in nucleosome remodelling complexes [30].

Evidence of genome-wide histone modifications in cancer [31] implies genome-wide DNA methylation defects. Direct evidence that DNA methylation plays a central role in chromosomal stability is that loss of DNA methylation of centromeric and pericentromeric loci is associated with large-scale chromosomal changes [32]. It seems highly probable that alterations in DNA methylation represent the fundamental defect that underlies the genomic instability which is characteristic of cancer cells [33-35].The widespread nature of the abnormalities in DNA methylation inferred from the above argument suggests that the methylation disturbance arises from a generalised defect, and it has been suggested that this crucial epigenetic error arises through lack of fidelity of epigenetic copying during stem cell mitosis [36,37]. The lack of fidelity in the vertical transmission of the epigenetic signal is ascribed, in adult malignancies, to mutations affecting the mechanism responsible for replication of the pattern of DNA methylation [38,39]. Mutations affecting the DNA methyltransferase 1 complex or the associated proof-reading and authentication mechanisms occurring in tissue stem cells as the initiating cause of carcinogenesis would be consistent with the age-dependent incidence of adult human cancers described by models $[40,41]$ essentially similar to those of Armitage and Doll [42]. Such a process affecting tissue stem cells would be consistent with a strong relationship between stem cell population size of individual tissues and their relative cancer incidence. Moreover, the likelihood of expression of the initiating mutation will be a function of the proliferation rate of specific tissue stem cells. Both these relationships have been demonstrated for human cancers by Tomasetti and Vogelstein [43].

\section{Conclusion}

The fundamental diagnostic abnormality of cancer cells is widespread disturbances of the genome with many abnormal derangements of genetic expression and rapid clonal evolution. This is the consequence of chromosomal instability (CIN) which is a cardinal feature of cancer cells. It is proposed that the basic metabolic process underlying this process is failure of fidelity of epigenetic copying during replication by a clone of tissue stem cells. The faulty epigenetic copying is attributed to one or more initiating mutations affecting the replication mechanism in the progenitor cell.During DNA replication the chromosomal structure is opened up and the nucleosomes separated. Under normal circumstances the histone framework is restored, partly from the conservative transfer of pre-existing $\mathrm{H} 3 / \mathrm{H} 4$ histone tetramers, and partly by recruitment of newly synthesised histones. The histone variants and their post-translational modification are determined by the methylation pattern of the replicated DNA, such that the histone chaperone complex in the replisome brings about an identical nucleosome assembly and the reformed chromatin structure is preserved in the division products [44].

However, failure to accurately copy the DNA methylation pattern will result in altered histone assembly giving rise to modified nucleosome structure, and hence chromosomal variation in the division products. It will be readily seen that with succeeding generations this process will lead to rapid divergent chromosomal structure and hence wide-ranging and variable sets of cellular characteristics and rapid clonal evolution of cells exhibiting abnormal properties, including cellular autonomy with loss of cooperative function within the organism, disorganized behavior, loss of territorial limitations, failure of appropriate responses to intercellular and inter-tissue signals, deranged metabolism and unregulated proliferative activity - the essential biological features of malignant cells.

\section{Acknowledgement}

I thank Mark Burkitt and Brian Morgan for helpful comments.

\section{References}

1. Saade E, Ogryzko VV (2014) Epigenetics: What is it about? Biopolymers and Cell 30(1): 3-9.

2. Kobayashi I (2001) Behavior of restriction-modification systems as selfish mobile elements and their impact on genome evolution. Nucleic Acids Research 29: 3742-3756.

3. Waddington CH (1942) The epigenome. Endeavour 1: 18-20.

4. Waddington CH (1962) New Patterns in Genetics and Development. Columbia University Press, New York, USA.

5. Holliday R, Pugh JE (1975) DNA modification mechanisms and gene activity during development. Science 187: 226-232.

6. Riggs AD (1975) X inactivation, differentiation, and DNA methylation. Cytogenet Cell Genet 14: 9-25.

7. Law JA, Jacobsen SE (2010) Establishing, maintaining and modifying DNA methylation patterns in plants and animals. Nat Rev Genet 11: 204220.

8. Kim JK, Samaranayake M, Pradhan S (2009) Epigenetic mechanisms in mammals. Cell Mol Life Sci 66: 596-612.

9. Richmond T, Finch JT, Rushton B, Rhodes D, Klug A (1984) The structure of the nucleosome core particle at $7 \AA ̊$ resolution. Nature 311: 532-537.

10. Luger K, Mäder AW, Richmond RK, Sargent DF, Richmond TJ (1997) Crystal structure of the nucleosome core particle at $2.8 \AA$ resolution. Nature 389: 251-260.

11. Allshire RC, Karpen GH (2008) Epigenetic regulation of centromeric chromatin: old dogs, new tricks? Nat Rev Genet 9: 923-937.

12. Amor DJ, Choo KH (2002) Neocentromeres: role in human disease, evolution and centromere study. Am J Hum Genet 71: 695-714.

13. Henikoff S, Ahmad K, Malik HS (2001) The centromere paradox: stable inheritance with rapidly evolving DNA. Science 293: 1098-1102.

14. Karpen GH, Allshire RC (1997) The case for epigenetic effects on centromere identity and function. Trends Genet 13: 489-496.

15. Sullivan BA, Blower MD, Karpen GH (2001) Determining centromere identity: cyclical stories and forking paths. Nat Rev Genet 2: 584-596.

16. Palmer DK, ODay K, Wener MH, Andrews BS, Margolis RL (1987) A 17kD centromere protein (CENP-A) copurifies with nucleosome core particles and with histones. J Cell Biol 104: 805-815. 
17. Blower MD, Sullivan BA, Karpen GH (2002) Conserved organisation of centromeric chromatin in flies and humans. Dev Cell 2: 319-330.

18. Palmer DK, ODay K, Trong HL, Charbonneau H, Margolis RL (1991) Purification of the centromere-specific protein CENP-A and demonstration that it is a distinctive histone. Proc natlAcad Sci USA 88: 3734-3738.

19. Greaves IK, Rangsamy D, Ridgway P, Tremethick DJ (2007) H2A.Z contributes to the unique 3D structure of the centromere. Proc natlAcad Sci USA 104: 525-530.

20. Masumoto H, Masukata H, Muro Y, Nozaki N, Okazaki T (1998) A human centromere antigen (CENP-B) interacts with a short specific sequence in alphoid DNA, a human centromeric satellite. J Cell Biol 109: 1963-1973.

21. Oda H, Okamoto I, Murphy N, Chu J, Price SM, et al. (2009) Monomethylation of histone H4-lysine 20 is involved in chromosome structure and stability and is essential for mouse development. Mol Cell Biol 29: 2278-2295.

22. Sullivan BA, Karpen GH (2004) Centromeric chromatin exhibits a histone modification pattern that is distinct from both euchromatin and heterochromatin. Nat Struct Mol Biol 11: 1076-1083.

23. Putiri EL, Robertson KD (2011) Epigenetic mechanisms and genome stability. Clin Epigenet 2: 299-314.

24. Jones PA, Laird PW (1999) Cancer epigenetics comes of age. Nat Genet 21: 163-167.

25. Jones PA, Baylin SB (2002) The fundamental role of epigenetic events in cancer. Nat Rev Genet 3: 415-428.

26. Feinberg AP, Ohlsson R, Henikoff S (2006) The epigenetic progenitor origin of human cancer. Nat Rev Genet 7: 21-33.

27. Jones PA, Baylin SB (2007) The epigenomics of Cancer. Cell 4: 683-692.

28. Nan X, Ng HH, Johnson CA, Laherty CD, Turnewr BM, et al. (1998) Transcriptional repression by the methyl-CpG-binding protein MeCP2 involves a histone deacetylase complex. Nature 393: 386-389.

29. Jones PL, Veenstra GJ, Wade PA, Vermaak D, Kass SU, et al. (1999) Methylated DNA and MeCP2 recruit histone deacetylase to repress transcription. Nat Genet 19: 187-191.

30. Zhang Y, Ng HH, ErdjumentBromage H, Tempst P, Bird A, et al. (1999) Analysis of the NuRD subunits reveals a histone deacetylase core complex and a connection with DNA methylation. Genes Dev 13:19241935.

This work is licensed under Creative Commons Attribution 4.0 License

Submission Link: https://biomedres.us/submit-manuscript.php
31. Fraga MF, Ballestar E, VilarGarea A, BoixChornet M, Espada J, et al. (2005) Loss of acetylation at Lys 16 and trimethylation at Lys 20 of histone H4 is a common hallmark of human cancer. Nat Genet 37: 391-400.

32. Gisselsson D, Shao C, TuckMuller CM, Sogorovic S, Palsson E, et al. (2005) Interphase chromosome abnormalities and mitotic missegregation of hypomethylated sequences in ICF syndrome cells. Chromosoma 114: 118-126.

33. Jones PA, Gonzalgo ML (1997) Altered DNA methylation and genome instability: a new pathway to cancer? Proc Natl Acad Sci USA 94: 21032105.

34. Li S, Wen YH, Wei YJ, Wang YH, Liu HB (2015) Aberrant DNA methylation and Genome Instability and Mutation in Cancer. Cancer Genetics and Epigenetics 3: 1-5.

35. Barra V (2014) DNMT1 and Genomic Instability in Cancer. J Mol Genet Med 8: 113-117.

36. Riley PA (2014) Failure of fidelity of vertical transmission of epigenetic patterning as the basis of cancer. Melanoma Res 24: 424-427.

37. Riley PA (2015) Cancer is the outcome of defective epigenetic copying of the pattern of selective gene activity in differentiated cells. Cancer Res Frontiers 1: 280-287.

38. Riley PA (2017) The Epigenetic Theory of Carcinogenesis: p53 as the Guardian of the Epigenome. J Oncol \&Canc Res 1:1-6.

39. Riley PA (2018) Epigenetics and Carcinogenesis: DNA Methylation Abnormalities Associated with Cancer and their Possible Source. Biomed J Sci \& Tech Res 2: 1-3.

40. Riley PA (2015) Age-specific Incidence of Malignancy in Relation to the Epigenetic Model of Cancer Progression. FGNAMB 1: 79-81.

41. Riley PA (2017) The Epigenetic Theory of Carcinogenesis: Investigation of the model of age-specific incidence. PRAS Open 1: 1-6.

42. ArmitageP, DollR(1954) The age distribution of cancer and a multi-stage theory ofcarcinogenesis. BritJCanc 8: 1-12.

43. Tomasetti C. Vogelstein B (2015) Variation in cancer risk among tissues can be explained by the number of stem cell divisions. Science 347: 7881.

44. Annunziato AT (2015) The Fork in the Road: Histone Partitioning During DNA Replication. Genes 6: 353-371.

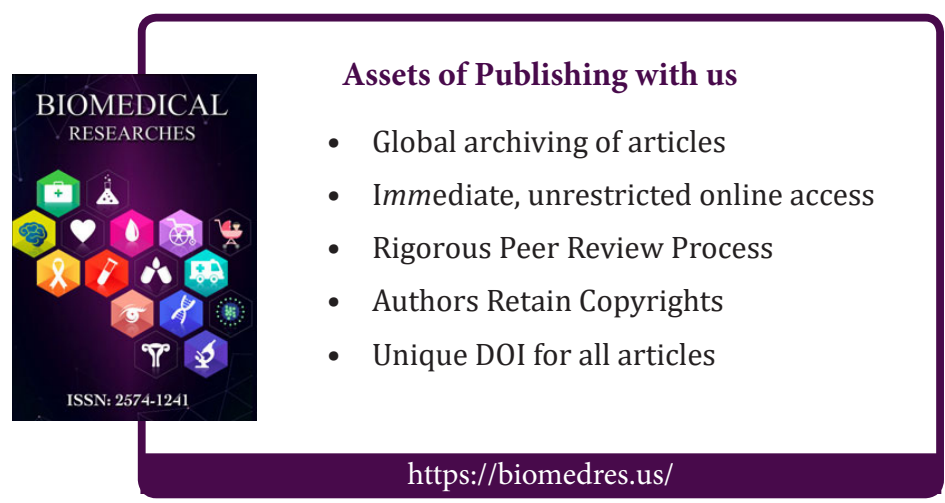

